\title{
A METHOD FOR STUDY OF NUCLEAR FUEL CYCLE SCENARIOS WITH AN INTENSIVE ELECTRICITY PRODUCTION DECLINE IN A SHORT PERIOD
}

\author{
Weifeng ZHOU ${ }^{1}$, Guillaume KRIVTCHIK ${ }^{1}$, and Patrick BLAISE ${ }^{2}$ \\ ${ }^{1}$ CEA, DES, IRESNE, DER, SPRC, Cadarache, F-13108 Saint Paul-Lez-Durance, France. \\ ${ }^{2}$ CEA, DES, IRESNE, DER, SPESI, Cadarache, F-13108 Saint Paul-Lez-Durance, France. \\ weifeng.zhou@,cea.fr
}

\begin{abstract}
Nuclear fuel cycle scenario study can be of benefit for decision-making in nuclear industry development. However, due to the lack of knowledge about the future, many scenario studies are subject to uncertainties. As a result, some parameters may be disrupted. Energy production of an entire nuclear fleet of interest is such a parameter. Its disruptive decline has a strong impact on the results of scenario studies. Resilience study against disruption of decline in energy production is required to anticipate possible failures of scenario studies. In such a resilience study, a large number of scenario trajectory simulations with different modes of decline are expected. It is too difficult to set the values of all scenario parameters in each trajectory manually. As a solution, a method is proposed in this paper to reduce the number of input parameters. A set of rules has been implemented as an intermediate layer between the decision-makers and the scenario code to drive the evolution of a nuclear fleet. In this case, a trajectory can be fully characterized by a few parameters. This method has been applied to a simplified academic nuclear fleet with two different modes of decline in energy production. The simulation results showed that the developed method is feasible. One should note that the scenario model in this paper is only used for academic purposes and does not correspond to any industrial strategy or policy.
\end{abstract}

KEYWORDS: nuclear fuel cycle scenario, electricity production decline, nuclear fleet evolution

\section{INTRODUCTION}

Nuclear fuel cycle scenarios are considered as a powerful decision-making tool thanks to their abilities to make projections of industrial strategies and to access the associated impacts on the nuclear fuel cycle system. As scenario studies are usually devoted to exploring possible prospective developments of a nuclear fleet of interest, they are subject to uncertainties due to the lack of knowledge about the future at the time of study. As a consequence, some parameters may be disrupted as time passes. Energy production of an entire nuclear fleet of interest is such a parameter. Its disruptive decline has a strong impact on the results of scenario studies as it could impose an early shutdown on some reactors. A scenario study without considering the possibility of declining energy production in the future may fail. For instance, the delicate material equilibriums in the fuel cycle chains could be disrupted by the early decommissioning of some reactors due to the decline in energy production, making the scenario trajectories unfeasible. Resilience study [1] should be carried out to avoid such failure. In a resilience study against the disruption of decline in energy production, a large number of scenario trajectory simulations with different modes of decline (decline level and decline dates) are expected. But with the 
high dimensionality of input parameters in a scenario trajectory (usually over hundreds of parameters), it is impossible to set their values one by one manually. One needs a way of allowing the automatic set-up of these parameters according to the mode of decline.

As a solution, a method is proposed in this paper to insert an intermediate layer between the scenario code and the decision-makers, as seen in Fig.1. In this method, the evolution of a nuclear fleet, such as the commissioning and decommissioning of reactors as well as the deployment of MOX fuel in reactors, is driven by a set of rules according to a given historical trajectory and a small number of parameters imposed by the decision-makers, including the decline in energy production. In this paper, the method is applied to a simplified academic nuclear fleet as a proof of concept. Two scenario trajectories with different decline levels in energy production are given as a demonstration for this method. The scenario simulations are performed with the sped-up version of the COSI6 code developed by the CEA Nuclear Energy Division [2]. One should mention that the scenario model detailed in the forthcoming paragraphs is constructed only for academic purposes and does not reflect any current industrial strategy or policy.

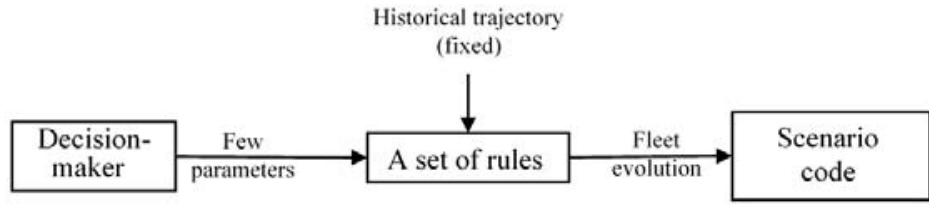

Figure 1 Developed method as an intermediate layer to drive evolution of a nuclear fleet

\section{METHOD}

\subsection{General Assumptions}

In this paper, a simplified academic nuclear fleet is considered, which is composed of 58 PWR. According to their electrical power, these reactors can be divided into three groups: 34 at $900 \mathrm{MWe}, 20$ at $1300 \mathrm{MWe}$ and 4 at 1450 MWe. 22 reactors from the 900 MWe level are initially 30\% partially fueled with MOX fuels in their cores, and the rest of the reactors load 100\% UOX fuels. All of these 58 PWR were commissioned between 1978 and 2000. More details can be found in [3]. In this paper, it is supposed that the EPR (European Pressurized Reactor) will be gradually commissioned to replace the old PWR after the decline in electricity production. The reactors are individually modeled, and their characteristics are shown in Table I.

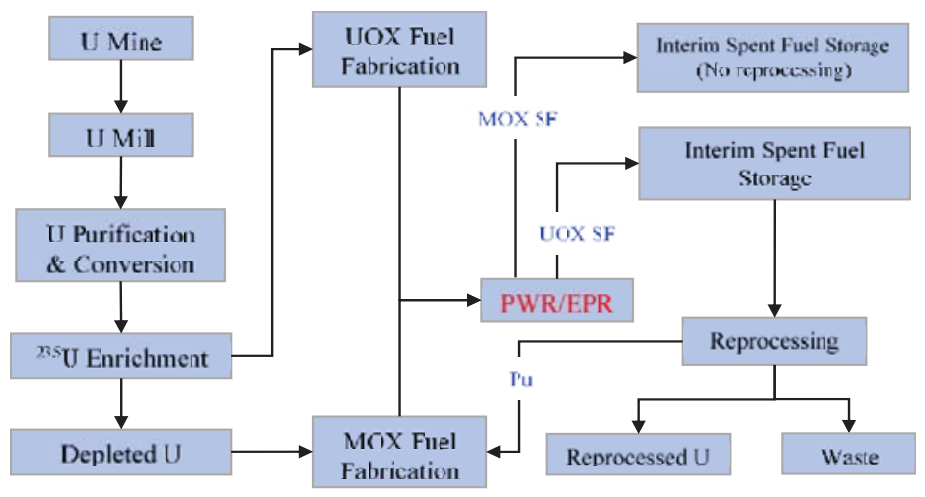

Figure $2 \mathrm{Pu}$ recycled in PWR/EPR

The recycling strategy considered is shown in Fig.2. The fuel fabrication time is fixed at 2 years for both UOX and MOX fuels. The minimum cooling time before the reprocessing of spent fuels is 5 years. 
Table I Characteristics of reactors $[3,4]$

\begin{tabular}{|c|c|c|c|c|}
\hline \multirow{2}{*}{ Reactor type } & \multicolumn{3}{|c|}{ PWR } & \multirow{2}{*}{ EPR } \\
\cline { 2 - 4 } & $900 \mathrm{MWe}$ & $1300 \mathrm{MWe}$ & $1450 \mathrm{MWe}$ & \\
\hline Power (MWth) & 2800 & 3800 & 4300 & 4500 \\
\hline Power (MWe) & 900 & 1300 & 1450 & 1529 \\
\hline Net yield (\%) & 32.1 & 34.2 & 33.7 & 34.0 \\
\hline Load factor (\%) & 75.2 & 75.2 & 75.2 & 83.0 \\
\hline Mass in core (tHM) & 72.5 & 104 & 110 & 120 \\
\hline Irradiation time (EFPD) & $3 \times 423$ & $3 \times 410.5$ & $3 \times 392.2$ & $3 \times 460$ \\
\hline Average burnup (GWd/tHM) & 49 & 45 & 46 & 51.8 \\
\hline
\end{tabular}

\subsection{Assumptions on Annual Total Electricity Production}

In our study, a strong decline in electricity production of the nuclear fleet is considered, as shown in Fig.3. According to [5], the decommissioning of reactors has to be previewed at least three years ahead for reasons of labor placement decisions and associated staffing costs. Hence, it is supposed in this paper that the decline in electricity production by decommissioning reactors starts in 2023 , with annual electricity production $D_{0}=409.2 \mathrm{TWe} \cdot \mathrm{h}$. The decline is linear with respect to time and ends in 2035. After 2035, the annual total electricity production is assumed to stay stable at the level of $\alpha \cdot D_{0}$ where $\alpha$ is defined as the ratio between the annual electricity productions after and before the reduction. The scenario simulation ends in 2075, making a long observation period after the replacement of current reactors by 2060 for the sake of ensuring the suitability of results.

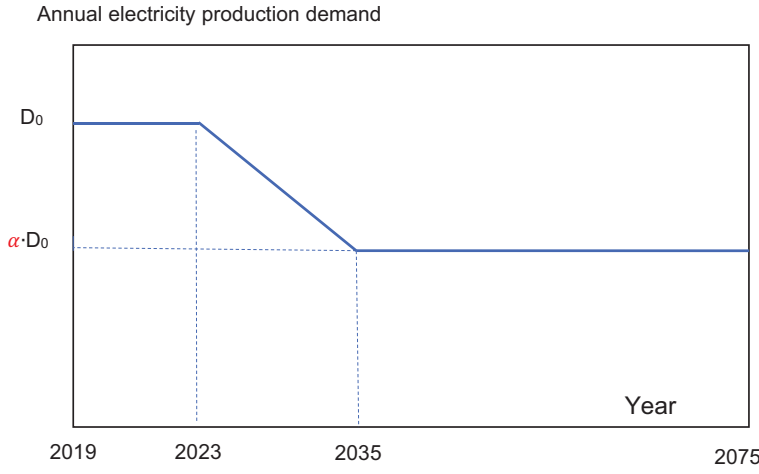

Figure 3 Assumption on annual total electricity production

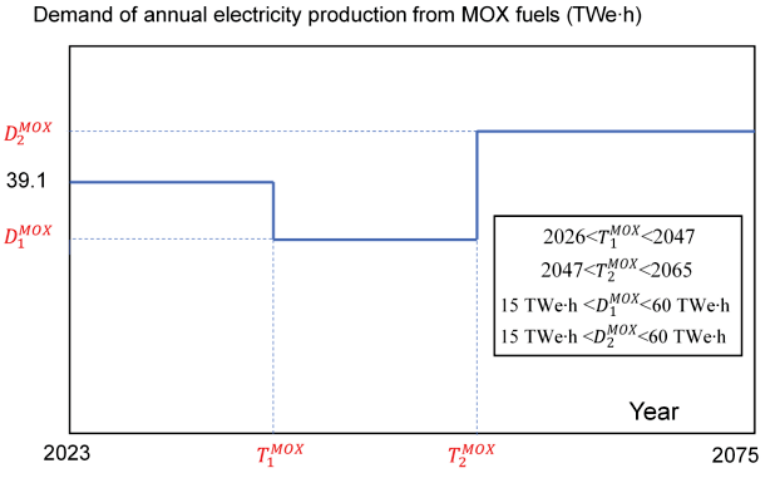

Figure 4 Assumption on annual electricity production from MOX fuels

Several rules have been implemented in the scenario model in the form of an algorithm to determine the commissioning and decommissioning of reactors according to the given assumption of annual total electricity production. The rules for decommissioning reactors are the following:

1) A reactor can only be decommissioned at the end of the irradiation cycles.

2) The lifespan of a reactor can not exceed 60 years.

3) After a decennial visit ${ }^{1}$, the reactor has to operate for at least 7 years (arbitrarily chosen duration) for economic reasons.

4) The oldest reactors are decommissioned preferentially for economic considerations.

\footnotetext{
${ }^{1}$ The decennial visit is a periodic examination imposed on a reactor for a safety review to authorize the operation of next ten years.
} 
5) The decision to decommission reactors is made according to the imposed annual total electricity production set-points.

Correspondingly, the rules for the commissioning of new reactors are given as:

1) The type of new reactors is restricted to EPR and their commissioning dates are determined by the difference between the annual electricity production and the imposed set-points.

2) The commissioning rate can not exceed 2 EPR per year for the sake of smoothing the investments. To do so, the decommissioning dates of old reactors can be adjusted if necessary.

\subsection{Assumptions on Deployment of MOX Fuels in Reactors}

As the reduction in nuclear electricity production progresses, some reactors consuming MOX fuels may be decommissioned, and the proportion of UOX/MOX reactors can no longer be maintained, which could lead to a spent fuel storage crisis [6]. To solve this problem, a MOX fuel deployment strategy is considered in the developed method.

The deployment of MOX fuels is driven by the set-points of annual electricity production from MOX fuels, which are shown in Fig.4. There exist three periods in which the annual electricity production from MOX fuels is constant: i) from 2023 to year $T_{1}^{M O X}$ with a production $39.1 \mathrm{TWe} \cdot \mathrm{h}$; ii) from year $T_{1}^{M O X}$ to year $T_{2}^{M O X}$ with a production $D_{1}^{M O X}$; iii) after year $T_{2}^{M O X}$ with a production $D_{2}^{M O X}$. To realize the deployment of MOX fuels according to this profile, several rules have been implemented in the model in the form of an algorithm to MOX and de-MOX reactors. The rules to MOX reactors are the following:

1) The reactors can only be MOXed at the beginning of irradiation cycles.

2) The reactor to be MOXed should have gone through at least one equilibrium irradiation cycle when the first MOX fuel is loaded.

3) Once a reactor is MOXed, it has to go through at least one "nominal" irradiation cycle where the whole core is MOXed at $30 \%$.

4) A longer operating time with MOX fuel is preferable, in order to reduce the number of times to MOX and de-MOX reactors.

5) A reactor can not be MOXed more than once in its life.

6) The decision to MOX reactors is made according to the imposed set-points (as in Fig.4).

The rules to de-MOX the reactors into UOX ones are given as:

1) The reactors can only be de-MOXed at the ends of irradiation cycles.

2) Once a reactor is de-MOXed, it has to go through at least one "nominal" irradiation cycle where the whole core is fueled with UOX fuels at $100 \%$.

3) Shorter operating time with UOX fuel after de-MOXing is preferable, in order to reduce the number of times to MOX and de-MOX in the nuclear fleet.

4) The decision to de-MOX reactors is made according to the imposed set-points (as in Fig.4).

\subsection{Assumptions on Reprocessing Capacity}

In this scenario model, it supposes that there exist three periods in which the reprocessing capacity stays constant: i) from 2023 to year $T_{1}^{C}$ with a capacity $920 \mathrm{tHM} / \mathrm{year}$; ii) from year $T_{1}^{C}$ to year $T_{2}^{C}$ with a capacity $C_{1}$; iii) after year $T_{2}^{C}$ with a capacity $C_{2}$. $\left(2026<T_{1}^{C}<2045<T_{2}^{C}<2063 ; 500 \mathrm{tHM} /\right.$ year $<C_{1}$, $C_{2}<1000 \mathrm{tHM} /$ year). 


\section{RESULTS AND DISCUSSIONS}

In the scenario model, thanks to the rules presented above, a trajectory can be fully characterized by 9 parameters $\left(\alpha, T_{1}^{M O X}, T_{2}^{M O X}, D_{1}^{M O X}, D_{2}^{M O X}, T_{1}^{C}, T_{2}^{C}, C_{1}, C_{2}\right)$, whose dimensionality is much smaller than that of scenario parameters in a trajectory. To evaluate the impact of electricity decline on the nuclear fleet, two trajectories with different declines in electricity production are arbitrarily given as the following:

- Traj. A: $\left(\alpha=0.7, T_{1}^{M O X}=2028, T_{2}^{M O X}=2058, D_{1}^{M O X}=26.0\right.$ TWe $\cdot \mathrm{h}, D_{2}^{M O X}=32.2$ TWe h, $T_{1}^{C}=2026$, $T_{2}^{C}=2052, C_{1}=672.0 \mathrm{tHM} /$ year, $C_{2}=728.4 \mathrm{tHM} /$ year $)$

- Traj. B: $\left(\alpha=0.8, T_{1}^{M O X}=2026, T_{2}^{M O X}=2055, D_{1}^{M O X}=27.1\right.$ TWe $\cdot h, D_{2}^{M O X}=30.0$ TWe h, $T_{1}^{C}=2026$, $T_{2}^{C}=2055, C_{1}=645.8 \mathrm{tHM} /$ year, $C_{2}=732.3 \mathrm{tHM} /$ year)

After the decline, the nuclear energy production in Traj. A is reduced to $70 \%$ of the level in 2023 (i.e. $50 \%$ of nuclear share) while the corresponding value in Traj. B is $80 \%$ (i.e. $58 \%$ of nuclear share). The demands of energy production from MOX fuels and the settings of reprocessing capacities in both trajectories are similar.

\subsection{Electricity Production and Reactor Lifespans}

Electricity productions are shown in Fig.5. First of all, the total electricity productions given by simulation for both trajectories generally coincide with the set-points, despite some small fluctuations due to the decommissioning and commissioning of reactors.
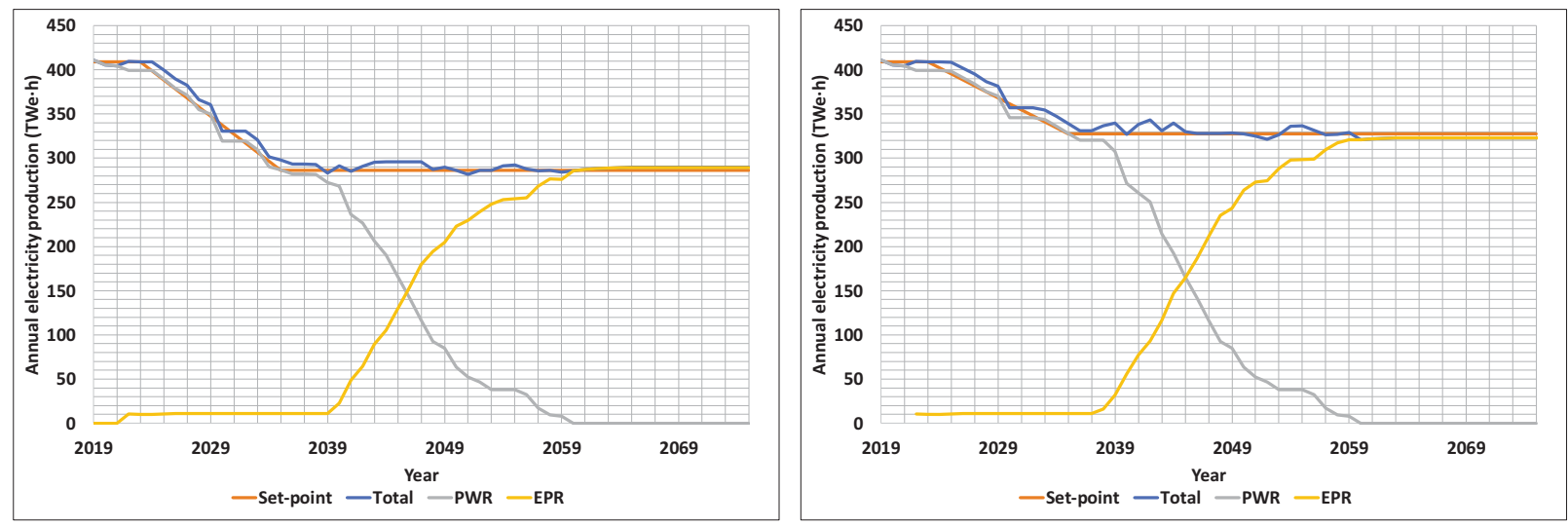

Figure 5 Annual electricity production in the nuclear fleet (left: Traj. A; right: Traj. B)

All PWR of the nuclear fleet are completely shut down before 2060. The distributions of their lifespans are demonstrated in Fig.6. According to [7], the two oldest PWR will be gradually replaced by an EPR between 2020 and 2022. The rest of the PWR are decommissioned just before their next decennial visits in both trajectories, with the differences covering from three years to less than one year. The average lifespan of the 58 PWR in Traj. A is about 55.3 years, around 1.2 years less than that in Traj. B. It means that a $10 \%$ greater reduction in electricity production can lead to a lifespan loss of over one year for each PWR in the nuclear fleet.

Large-scale commissioning of EPR is required between 2039 and 2060 for both trajectories according to Fig.5. They are commissioned with a pace smaller than 2 reactors per year in the both trajectories, making the construction of reactors smooth and avoiding the "Cliff Effect" problem [8]. When the replacement of the old PWR is finished in around 2060, the numbers of commissioned EPR in Traj. A and Traj. B are respectively 26 and 29 . 

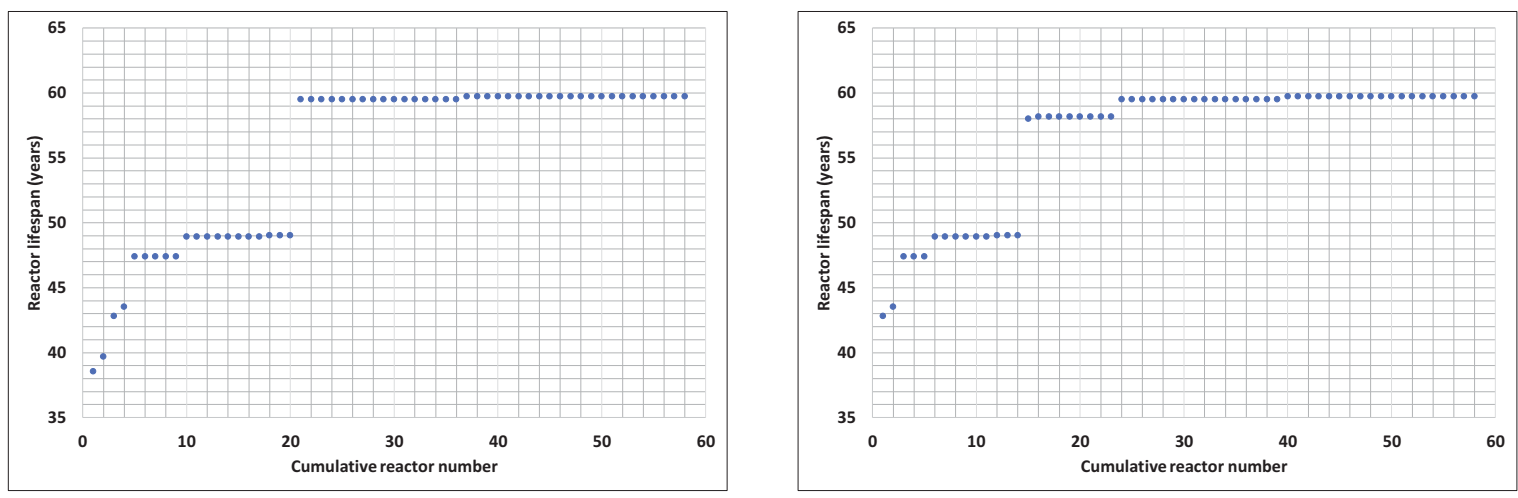

Figure 6 Distribution of PWR lifespans (left: Traj. A; right: Traj. B)

\subsection{Deployment of MOX Fuels in Reactors}

The electricity production from MOX fuels is presented in Fig.7. One can firstly observe that there exist differences between the simulation results and the set-points in both trajectories as the reactors are individually modeled and a certain level of tolerance is considered in the model. In the period between 2035 and 2060, there are some fluctuations due to the large-scale shutdown and MOXing of reactors. Table II summarizes the deployment of MOX fuels in both trajectories. It shows that the nuclear fleet can meet the imposed electricity production demand from MOX fuels without repeating the processes of MOXing and de-MOXing more than one time, despite the decline in electricity production.
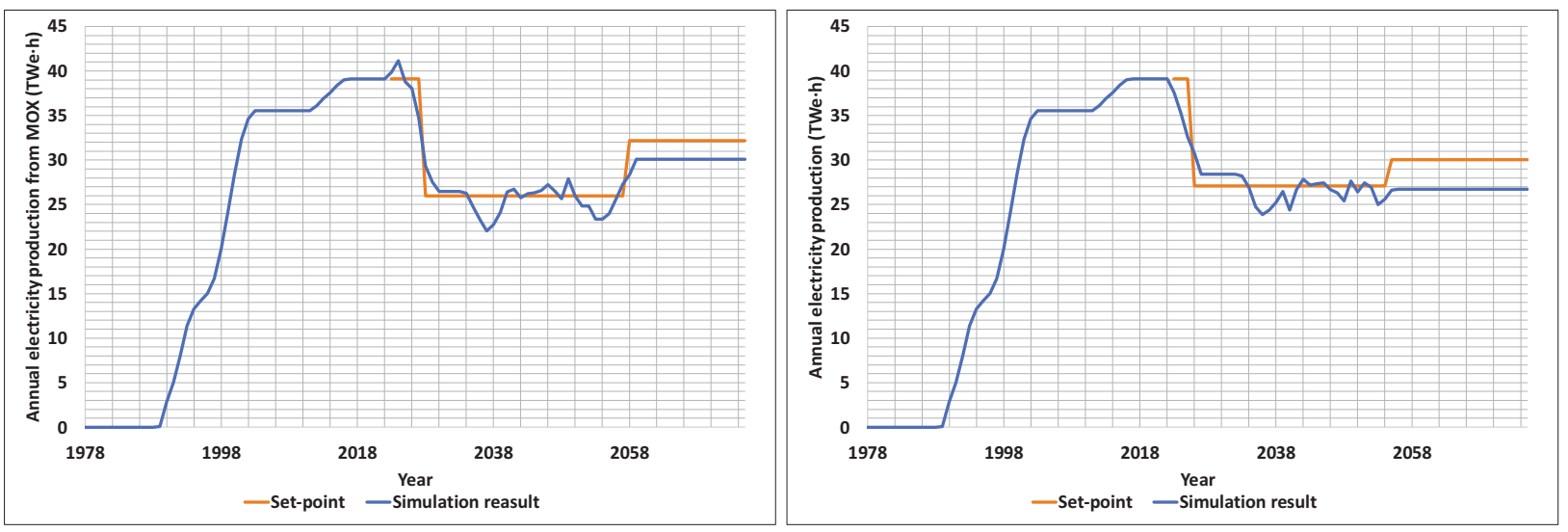

Figure 7 Electricity production from MOX fuels (left: Traj. A; right: Traj. B)

Table II Summary for deployment of MOX fuels

\begin{tabular}{|c|c|c|c|}
\hline \multicolumn{1}{|c|}{ Trajectory } & A & B \\
\hline \multirow{4}{*}{$\begin{array}{c}\text { Number of } \\
\text { reactors }\end{array}$} & Reactors with 100\% UOX in whole life & 44 & 48 \\
\cline { 2 - 4 } & $\begin{array}{c}\text { Reactors fueled with 30\% MOX until } \\
\text { decommissioning }\end{array}$ & 30 & 24 \\
\cline { 2 - 4 } & $\begin{array}{c}\text { Reactors through MOXing and de-MOXing } \\
\text { process once }\end{array}$ & 10 & 15 \\
\cline { 2 - 4 } & Total & $\begin{array}{c}84(58 \text { PWR + 26 } \\
\text { EPR) }\end{array}$ & $\begin{array}{c}87 \text { (58 PWR + 29 } \\
\text { EPR) }\end{array}$ \\
\hline
\end{tabular}




\subsection{Separated Pu Inventory and Fresh MOX Fuel Characteristics}

The inventories of $\mathrm{Pu}$ in the separated stock in the both trajectories are shown in Fig.8. They vary between 10 and 30 tons of $\mathrm{Pu}$, which is reasonable for both $\mathrm{Pu}$ supply and $\mathrm{Pu}$ storage.

Fig.9 shows the evolution of Pu content in fresh MOX fuels. In this scenario model, the decommissioning of MOX reactors is carried out in their last irradiation cycle with specific MOX fuel batches whose Pu content is reduced according to their shorter residence time in the core. As a consequence, one can see in Fig.9 that the Pu content can sometimes approach 6\%, corresponding to the loading of specific shutdown MOX fuel batches in the cores. Generally, the Pu content always stays below $11 \%$ for both trajectories during the simulation.

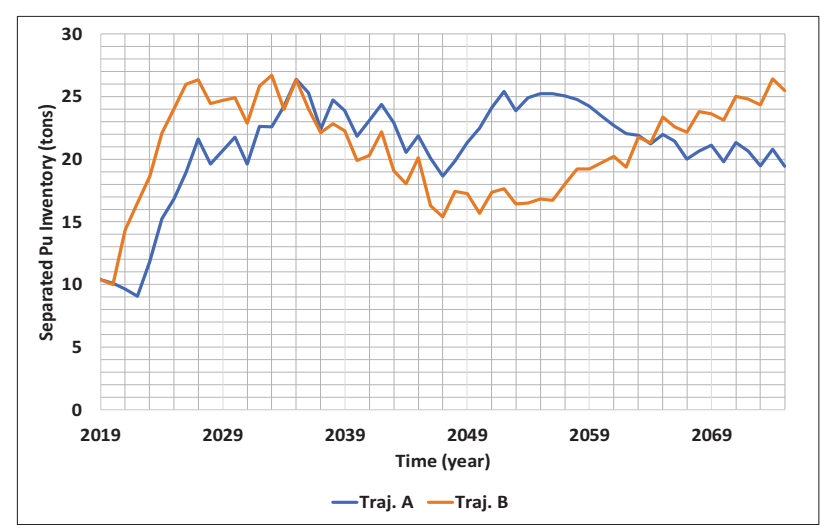

Figure 8 Separated Pu Inventory

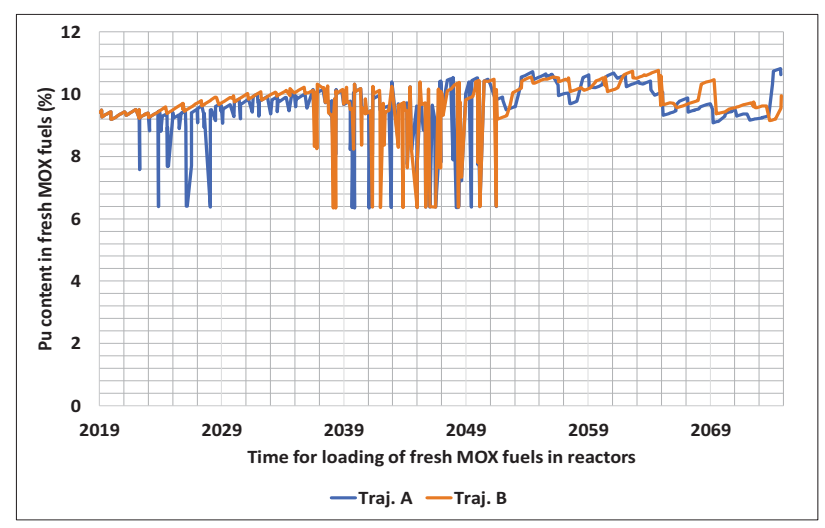

Figure $9 \mathrm{Pu}$ contents in fresh MOX fuels

\subsection{Natural Uranium Consumption and Spent Fuel Inventory}

Fig.10 shows the consumption of natural uranium in both trajectories. Before the decline in energy production, from 2000 to 2019, the simulated nuclear fleet consumes natural uranium with a rate around 8300 tons/year; after the decline, from 2036 to 2075 the natural uranium consumption rates are respectively 5500 tons/year in Traj. A and 6300 tons/year in Traj. B.

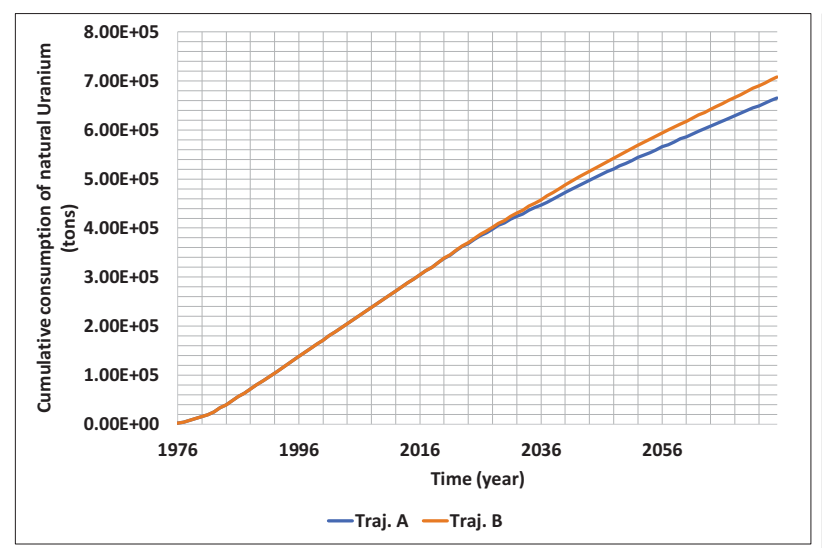

Figure 10 Consumption of natural uranium

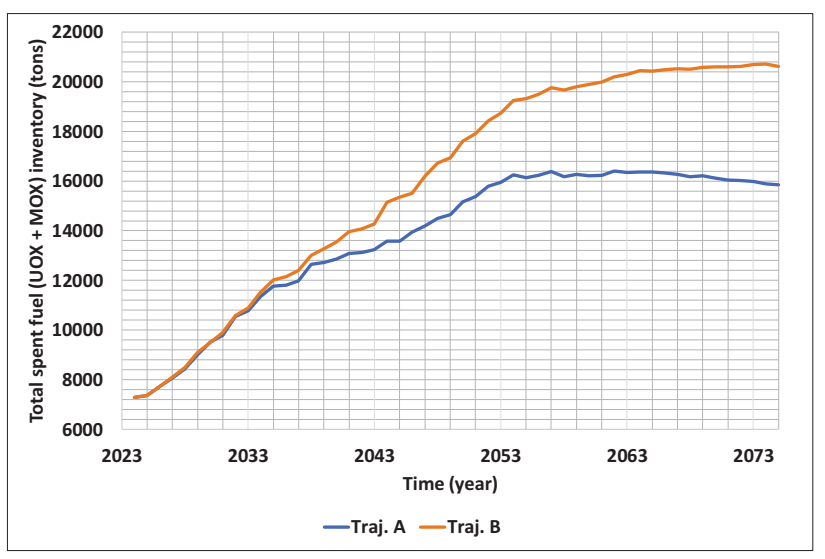

Figure 11 Total spent fuel inventory

As shown in Fig.11, the total spent fuel inventories in both trajectories are quasi-stable after the replacement of the old PWR in around 2060. Though with less difference in the settings of reprocessing 
capacities for both trajectories, Traj. A produces around 4800 tons of spent fuels less than Traj. B at the end of the simulation in 2075, thanks to its smaller scale of nuclear fleet.

\section{CONCLUSIONS}

In a resilience study against the disruption of decline in energy production, a large number of scenario trajectory simulations with different modes of decline are expected and it is impossible to set the values of all scenario parameters one by one manually in each trajectory because of their high dimensionality. To solve this problem, this paper proposes a method to use a set of rules to drive the evolution of a nuclear fleet. In this case, the number of input parameters can be significantly reduced. As an example, this developed method is applied to a simplified academic nuclear fleet and two trajectories with different declines in energy production are given. Each trajectory is fully characterized by only 9 parameters. Their simulation results showed that the developed method is feasible. Generally, the rules to drive the evolution of a nuclear fleet can be different from case to case and they should be selected according to the considerations of decision-makers. In the follow-up work, this method should be integrated into the resilience study considering the uncertainty of decline in energy production.

The scenarios modeled in this paper are built only for academic studies and do not reflect industrial strategy or policy.

\section{REFERENCES}

[1] W. Zhou, G. Krivtchik and P. Blaise, "A First Approach to Resilience of Nuclear Fuel Cycle Scenarios," Proceedings of GLOBAL 2019, Seattle, September 22-26, 2019 (2019).

[2] G. Krivtchik, "Analysis of uncertainty propagation in nuclear fuel cycle scenarios," PhD thesis, Université Grenoble Alpes (2014).

[3] F. Courtin, "Etude de l'incinération du plutonium en REP MOX sur support d'uranium enrichi avec le code de simulation dynamique du cycle CLASS," PhD thesis, Université Bretagne Loire (2017).

[4] M. Tiphine, C. Coquelet-Pascal, G. Krivtchik, R. Eschbach, C. Chabert, B. Carlier, M. CaronCharles, G. Senentz, L. Van den Durpel, C. Garzenne and F. Laugier, "Simulations of Progressive Potential Scenarios of Pu Multirecycling in SFR and Associated Phase-Out in The French Nuclear Power Fleet," Proceedings of GLOBAL 2015, Paris, September 20-24, 2015 pp 5326 (2015).

[5] Nuclear Energy Insider, "Operators told to plan shutdowns three years ahead, focus on labor," [Online]. Available: https://analysis.nuclearenergyinsider.com/operators-told-plan-shutdowns-three-yearsahead-focus-labor (2016).

[6] Nuclear Engineering International, "France needs Mox to avoid spent fuel storage crisis," [Online]. Available: https://www.neimagazine.com/news/newsfrance-needs-mox-to-avoid-spent-fuelstorage-crisis-6820865 (2018)

[7] Réseau de Transport d'Electricité, "Bilan prévisionnel de l'équilibre offre-demande d'électricité en France - Edition 2018," Réseau de Transport d'Electricité (2018).

[8] C. Bataille and C. Birraux, "Lifetime of Nuclear Power Plants and New Designs of Reactors," French National Assembly (2003). 